\title{
V - A ONU e a Administração Internacional de Recursos Humanos
}

Reconhecendo tudo isso e lidando, segundo se viu, com uma família de organizações composta de 16 membros e de quase 50.000 servidores espalhados pelo mundo, tem a ONU dedicado especial atenção ao problema da administração de recursos humanos em ambiente internacional ou multinacional.

Assim, no correr dos tempos foi ela criando vários órgãos assessores de administração de recursos humanos, que assistem, em função de staff, aos seus órgãos decisórios em relação à matéria.

Esses órgãos assessores são, atualmente, em número de três, a saber :

1) ICSAB (International Civil Service Advisory Board), que, como o seu nome o está indicando, cuida dos principais aspectos da política de pessoal da ONU e sua família de organizações.

2) ECPA (Expert Committee on Post-Adjustment), que, como o seu nome também o indica, cuida, especificamente, do sistema de post-adjustment (43).

3) CCAQ (Consultative Committee on Administrative Questions), o primeiro dos órgãos assessores em matéria administrativa criado na ONU. Durante algum tempo, assessorou com exclusividade os órgãos decisórios em todos os aspectos relacionados com a administração em geral, inclusive a obtenção e utilização de recursos humanos. Posteriormente, transferiu parte de suas atribuições ao ICSAB e ao ECPA, continuando, porém, a assessorar os órgãos decisórios em matérias administrativas, de modo geral, inclusive pessoal, quando solicitado ou em questões que escapam a competência do ICSAB e ECPA.

A esses três órgãos de assessoramento, girando em torno da Comissão Administrativa de Coordenação (Administrative Committee on Co-ordination),

(43) O post-adjustment é um pagamento suplementar pela ONU aos seus funcionários internacionais em função do custo de vida do local em que eles servem, conforme já foi esclarecido. 
compete, em suma, velar pela manutenção e aperfeiçoamento do sistema comum de salários, vantagens e outras condições de serviço, que prevalece no seio da família das Nações Unidas.

No momento, dando mais um passo adiante na sua política pioneira no campo da administração internacional de recursos humanos, acaba a ONU de instituir a Comissão de Serviço Civil Internacional (International Civil Service Commission), que, para o bom entendimento do leitor brasileiro, será uma espécie de DASP colegiado e de âmbito internacional, ou, melhor ainda, a Civil Service Comission norte-americana elevada à categoria internacional.

Ao novo órgão - cuja criação deveria ter-se dado na XXVIII Assembléia Geral (1973), mas ficou adiada para a XXIX — cabe, em suma, a missão de procurar estabelecer para toda a família de organizações das Nações Unidas, segundo as próprias palavras de seu Estatuto, "a single unified international civil service through the application of common personnel standards, methods and arrangements".

Especificamente, é sua atribuição, de acordo ainda com o citado Estatuto, fazer recomendações à Assembléia Geral das Nações Unidas no que concerne :

a) aos princípios básicos para o estabelecimento das condições de serviço de pessoal;

b) às escalas de salário e de post-adjustment para o pessoal de categoria profissional e escalões superiores;

c) ao staff assessment (44).

No desempenho de suas atribuições, cabe à Comissão do Serviço Civil Internacional :

1) estabelecer os métodos de acordo com os quais serão aplicados os princípios relativos à determinação das condições de serviço;

2) fixar os níveis das vantagens e benefícios (exceto pensões), as condições de habilitação aos mesmos e os padrões de viagens em serviço;

3) classificar os locais de serviço para fins de concessão do post-adjustment;

4) estabelecer padrões de classificação de cargos para todas as categorias de pessoal em áreas de atividades comuns a mais de uma organização;

(44) Plano da ONU destinado, basicamente, a compensar seus servidores internacionais - isentos do pagamento de impostos relativos às suas atividades profissionais - por tributação dessa natureza, que, porventura, venha a recair sobre eles em virtude de legislação nacional em sentido contrário.

R. Serv. públ., Brasília, 109 (4) out./dez. 1974 
5) propor às organizações-membro:

a) padrões de recrutamento;

b) o desenvolvimento de fontes de recrutamento, inclusive o estabelecimento de registros centrais de candidatos qualificados, principalmente para os níveis iniciais de admissão;

c) a organização de provas competitivas ou processos alternativos de seleção;

d) o desenvolvimento de carreiras, programas de treinamento, inclusive interorganizacionais, e a avaliação do pessoal;

e) o estabelecimento de disposições comuns sobre pessoal;

6) fazer recomendações às organizações-membro da família das Nações Unidas sobre toda e qualquer outra matéria que ela considere necessária para a melhor colimação dos objetivos do Estatuto.

Com o estabelecimento da Comissão de Serviço Civil Internacional o mais alto órgão consultivo em administração internacional de recursos humanos - deverão deixar de existir o ICSAB e o ECPA na estrutura da família de organizações das Nações Unidas.

E instalando aquela Comissão, dá a ONU, no campo da administração de recursos humanos a nível internacional, um exemplo que poderá ser útil, não só a outras organizações internacionais, como até mesmo a muitas empresas multinacionais.

\section{O Funcionário Internacional}

Graças, principalmente à ONU, surgiu, assim, no mundo a figura do funcionário internacional, que difere, a muitos respeitos, do funcionário nacional e não se confunde com o diplomata, apesar de ter com este vários pontos em comum.

A principal peculiaridade do funcionário internacional é que - diversamente do diplomata e do funcionário nacional - deve ele lealdade, em primeiro lugar e acima de tudo, inclusive de seu próprio país de origem, à organização internacional a que serve, como determina, expressa e taxativamente, o art. 301.013 das Staff Regulations (Normas Básicas de Pessoal ou Estatuto de Pessoal) das Nações Unidas : 
"301.013 No desempenho de suas funções, os funcionários da Organização não procurarão nem aceitarão instruções de qualquer governo ou de qualquer outra autoridade externa à Organização." (45) .

Isso está também contido no juramento que os funcionários das Nações Unidas são obrigados a fazer, de acordo com o artigo 301.019 , ao assumir suas funções :

“301.019 Os funcionários da Organização subscreverão o seguinte juramento ou declaração :

"Eu solenemente juro (prometo, me obrigo a) exercer, com toda a lealdade, discrição e consciência, as funções a mim confiadas na qualidade de servidor civil internacional das Nações Unidas, desempenhar essas funções e regular minha conduta tendo em vista somente os interesses das Nações Unidas, e não procurar nem aceitar, no que concerne ao desempenho de meus deveres, instruções de qualquer governo ou de qualquer outra autoridade externa à Organização."

Durante o tempo em que ele serve às Nações Unidas fica, pois, o funcionário internacional como que com a sua nacionalidade "suspensa", se assim se pode dizer.

Isso, aliás, que à primeira vista parece estranho, é perfeitamente compreensível e justificado. Pois, se dentro da ONU, cada servidor internacional fizesse o jogo dos interesses de seu país e se pusesse inteiramente a serviço deles, a organização transformar-se-ia em autêntico "saco de gatos", cada um "puxando a brasa para a sua sardinha" e não trabalhando em prol da organização e, por conseguinte, da humanidade como um todo.

E este é precisamente, de acordo com a sua Carta, o objetivo supremo da Organização das Nações Unidas, surgida dos escombros da Segunda Guerra Mundial : servir à humanidade, procurando livrá-la da guerra, da fome, da miséria.

Como os diplomatas, gozam também os funcionários internacionais das Nações Unidas de imunidades e privilégios indispensáveis ao bom desempenho de suas funções. Isso é também necessário porque, sem tais privilégios e imunidades, ficaria, muitas vezes, o funcionário internacional tolhido em sua ação em prol da organização a que serve e representa. Não permite, porém, a ONU que haja abuso desses privilégios e imunidades ou que sejam eles usados exclusivamente no interesse pessoal do servidor, conforme se viu no capítulo anterior.

(45) Utilizaram-se, nesta e em outras transcriçōes, as Staff Regulations da FAO. Tais Regulations são, porém, basicamente padronizadas para a ONU e toda a sua família de Organizações.

R. Serv. públ., Brasília, 109 (4) out./dez. 1974 
Essas duas características não são, todavia, atribuídas ou reconhecidas aos funcionários internacionais de empresas multinacionais. A razão é simples. Estes, em verdade, são funcionários internacionais de empresas privadas, ao passo que os da ONU e outras organizações, que representam a conjugação de esforços de vários Estados soberanos, constituem, por assim dizer, funcionários internacionais públicos ou semipúblicos.

Há, assim, lugar para uma clara e básica distinção, no que concerne a status, entre o funcionário internacional dos organismos internacionais e os funcionários internacionais das empresas multinacionais.

Por outro lado, impõe-se a ênfase na denominação de funcionários internacionais de ambos esses tipos de organização porque, conforme já foi mencionado anteriormente, contam eles também com funcionários locais, recrutados nos próprios países em que estão situados e basicamente como os próprios nacionais desses países em suas atividades públicas ou empresariais. A esses funcionários não é reconhecido nenhum tipo de privilégio ou imunidade ou status especial, seja a qualquer título. Em algumas organizações, principalmente das Nações Unidas, já se está também desenvolvendo, conforme foi mencionado, uma terceira categoria de funcionários que se poderia chamar de semilocais : são aqueles - principalmente taquígrafos e datilógrafos bi-ou-multilingues, tradutores etc. - que deveriam ser recrutados localmente, mas, devido à sua falta no mercado local ou nacional de trabalho, são recrutados internacionalmente e adquirem, então, alguns dos privilégios, imunidades ou vantagens especiais do funcionário internacional.

Como se vê, a administração internacional já deu origem a novos tipos ou categorias de funcionários perfeitamente caracterizados e antes insuspeitados.

É para regularizar e disciplinar as relações desses novos tipos de funcionários com as organizações internacionais a que servem que a $\mathrm{ONU}$, pelo menos com vistas aos próprios domínios, ou seja, a sua família de organizações, acaba de criar a Comissão de Serviço Civil Internacional, com sede em Nova lorque e quinze membros recrutados, de preferência, entre especialistas de administração internacional de recursos humanos com larga experiência e elevadas qualificações profissionais (46).

(46) Para mais perfeito conhecimento, por parte do leitor interessado, do que é a Comissão do Serviço Civil Internacional das Nações Unidas, reproduzimos na íntegra, no Apêndice C, o seu Estatuto, aprovado na XXIX Assembléia Geral, recém encerrada.

R. Serv. públ., Brasília, 109 (4) out./dez. 1974 


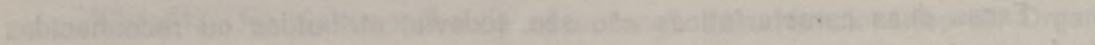

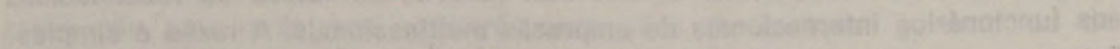

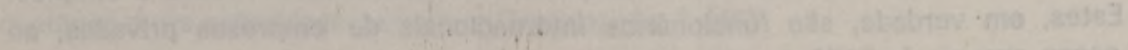

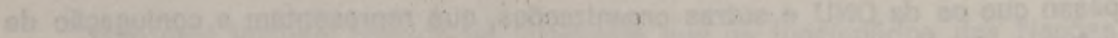

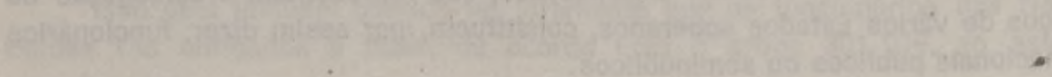

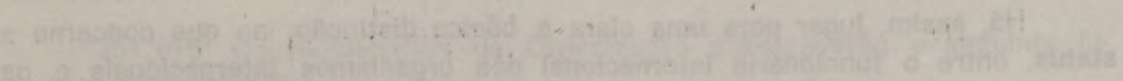
40.

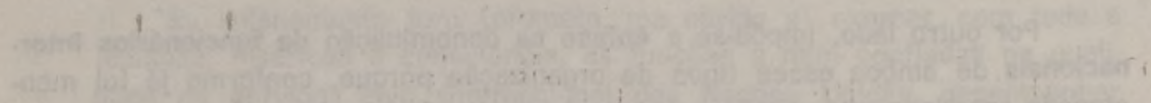

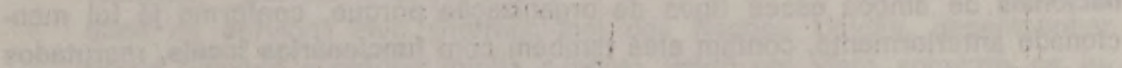

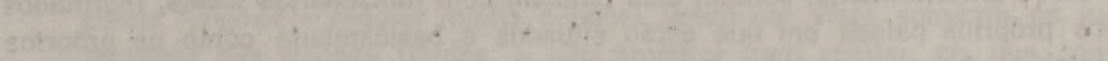

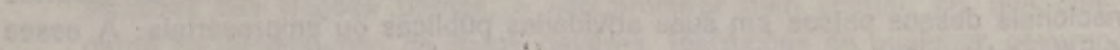

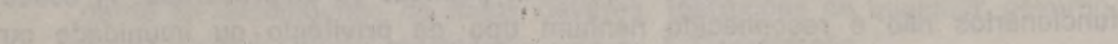

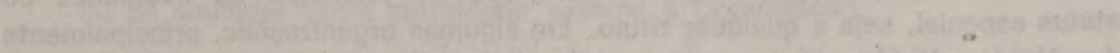

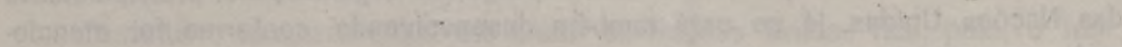

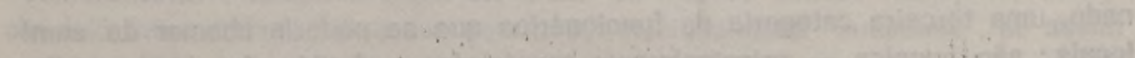

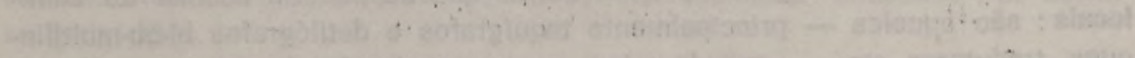

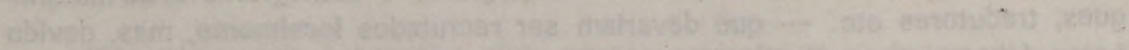

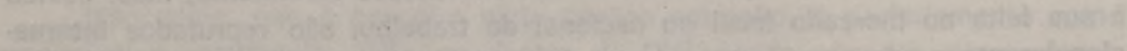

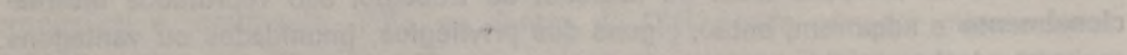

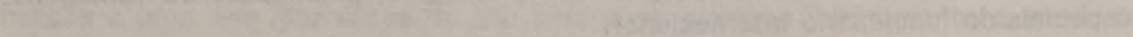

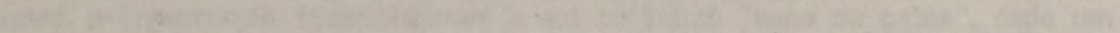

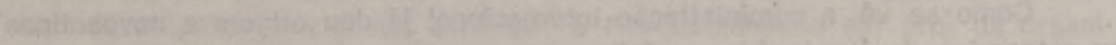

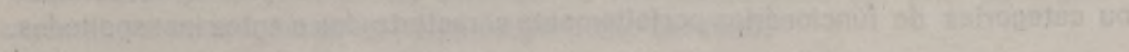

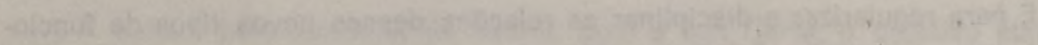

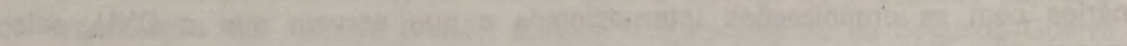

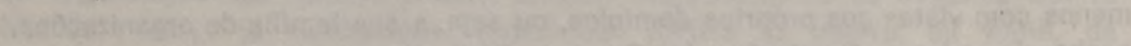

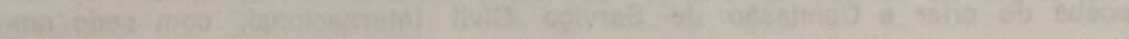

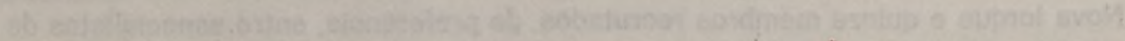

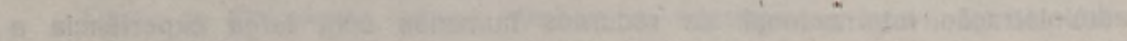

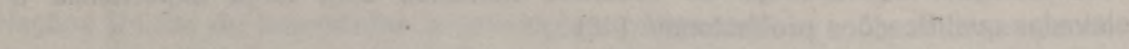
thas the

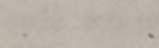

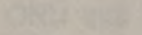
Yan

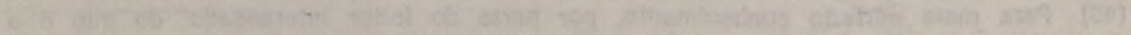

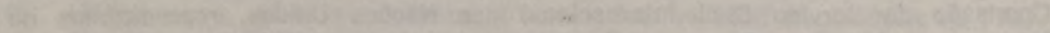

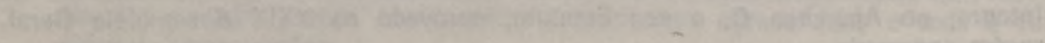

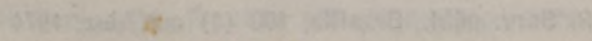

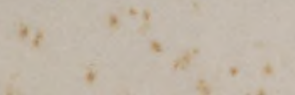

